\title{
The Relationship between Plasma ADAMTS 7 Level and Left Ventricular Remodeling after Acute Myocardial Infarction
}

\author{
MAI I. AL-SHARKAWY, M.Sc.*; AMAL HELMY, M.D.*; ABD EL-HAMEED, M.D.*; \\ WESAM S. MOHAMED, M.D.* and HANAN K. KASSEM, M.D.** \\ The Departments of Clinical Pathology* and Cardiovascular**, Faculty of Medicine, Tanta University
}

\begin{abstract}
Background: Left Ventricular (LV) dysfunction is the single strongest predictor of mortality following ST elevation myocardial infarction and is one of the most frequent and deadly complications of non ST elevation myocardial infarction. Degradation of Extracellular Matrix (ECM) causes progressive thinning and dilatation of infarct zone and contributes to serious complication as ventricular dilatation, dysfunction, aneurysm and even rupture. The matrix metalloproteinase-mediated degradation and remodeling of ECM plays an essential role in these disease processes.
\end{abstract}

Aim of the Study: It was to evaluate the relationship between plasma ADAMTS 7 level and left ventricular remodeling after acute myocardial infarction.

Patients and Methods: This study was carried on fifty cases that were divided into two main categories according to their health status. Diseased group included twenty five patients diagnosed as acute myocardial infarction with newly $\mathrm{S}-\mathrm{T}$ segment elevation. Based on their echocardiographic examination, patients were classified into two groups patients; a group of 16 patients with ejection fraction of more or equal 40 (group I; G1) and 9 patients with an ejection fraction of less than 40 (group II; G2). Control group included twenty five apparently healthy persons serving as controls (group III; G 3). All studied cases were subjected to detailed clinical history, thorough clinical examination, Electrocardiogram (ECG), trans-thoracic Echocardiography (ECHO), routine laboratory investigation included: Cardiac markers, renal function tests, liver function tests, lipid profile, serum electrolytes, complete blood picture and special laboratory investigation: Plasma adamts-7 levels measurement by ELISA technique.

Results: There was statistically significant increase in ADAMTS 7 concentration in group II (patients with ejection fraction $<40$ ) as compared with both group I (patients with ejection fraction > 40) and group III (controls), while there was no statistically significant difference between group I and group III. There was a statistically significant negative correlation between ADAMTS 7 concentration and both ejection fraction and fractional shortening in acute myocardial infarction patients. While there was a statistically significant

Correspondence to: Dr. Mai I. Al-Sharkawy,

The Department of Clinical Pathology, Faculty of Medicine, Tanta University positive correlation between ADAMTS 7 concentration and both left ventricular end diastolic diameter and left ventricular end systolic diameter in acute myocardial infarction patients.

Conclusion: The results of this research showed that there was a significant increase in the mean value of ADAMTS 7 levels in patients with ejection fraction $<40 \%$ than in patients with ejection fraction $>-40 \%$, so it may be used as a strong predictor for the development of left ventricular remodeling after acute myocardial infarction and this may be of a great value as a therapeutic target.

Key Words: Ventricular remodeling - ADAMTS 7 - Myocardial infarction.

\section{Introduction}

WORLDWIDE, Coronary Artery Disease (CAD) including acute myocardial infarction is one of the most frequent cause of death. Over seven million people every year die from CAD, accounting for $12.8 \%$ of all deaths. Myocardial Infarction (MI) describes the process of myocardial cell death caused by ischemia, or the perfusion imbalance between supply and demand within the coronary arteries resulting from an acute thrombotic process. The early recognition and diagnosis of acute MI is vital for the institution of therapy to limit myocardial damage and preserve cardiac function [1]

Virtually, Genome-Wide Association Studies (GAWS) proved that ADAMTS 7, as a member of this family has been implicated in development of coronary atherosclerosis as the risk of developing atherosclerotic disease has been found to be increased by $19 \%$ in individuals carrying single nucleotide polymorphism in ADAMTS 7 gene suggesting that ADAMTS 7 participates in early development and progression of atherosclerosis that leads to myocardial infarction [2].

Previous studies have shown that ADAMTS 7 serum level is highly sensitive to myocardial inf- 
arction ensuring the validity of its use as a biomarker in prognostic chemistry for a wide scope of diseases including heart disorders 3 .

\section{Aim:}

It was to evaluate the relation the relationship between plasma ADAMTS 7 level and left ventricular remodeling after acute myocardial infarction.

\section{Patients and Methods}

This study was done in Clinical Pathology Department in collaboration with Cardiology Department, Tanta University Hospital from January 2017 to July 2017. This study was done on fifty cases that were divided into two main categories according to their health status. Diseased group included twenty five patients diagnosed as acute myocardial infarction with newly S-T segment elevation. Based on their echocardiographic examination, patients were classified into two groups patients; a group of 16 patients with ejection fraction of more or equal 40 (group I; G 1 ) and 9 patients with an ejection fraction of less than 40 (group II; G2). Control group included twenty five apparently healthy persons serving as controls (group III; G 3).

All subjects of the study were subjected to the following: Detailed clinical history, thorough clinical examination, Electrocardiogram (ECG), transthoracic Echocardiography (ECHO) for assessment of left ventricular function. Routine laboratory investigation included cardiac markers, renal function tests, liver function tests, lipid profile, serum electrolytes, complete blood picture. Special laboratory investigation: Serum ADAMTS-7 levels measurement by ELISA technique.

Serum levels of ADAMTS 7 were estimated by Enzyme-Linked Immunosorbant Assay (ELISA) Kit supplied by Sun Red Biotechnology Company, purchased from Biogen Company.

Transthoracic echocardiographic examination was done using vivid 3 and vivd7, general electric corporation. Cardiac structure and function were assessed by echocardiographic cardiologist who was blind to the patient clinical status. Left Ventricular End Diastolic Diameter (LVEDD), Left Ventricular End Systolic Diameter (LVESD), Left Ventricular Ejection Fraction (LVEF) and Left Ventricular Fractional Shortening (LVFS) were calculated using M-mode method from parasternal long axis view. In the current study, ejection fraction parameter was used for stratification of the patients.

\section{Results}

The current study involved investigation of a total number of 25 patients and 25 controls. The subjects of the current study were assigned into 3 groups. Group I: It included 16 patients with acute myocardial infarction (ejection fraction $\geq 40$ ) diagnosed by echocardiogram. Group II: It included 9 patients with acute myocardial infarction (ejection fraction <40). Group III: It included 25 healthy individuals served as controls.

Table (1) presents the demographics and laboratory data of the case control study population.

Table (1): Demographic and laboratory data of the studied groups.

\begin{tabular}{|c|c|c|c|c|}
\hline & $\begin{array}{c}\text { GI } \\
(n=16)\end{array}$ & $\begin{array}{c}\text { GII } \\
(n=9)\end{array}$ & $\begin{array}{c}\text { GIII } \\
(n=25)\end{array}$ & $\begin{array}{c}p \text { - } \\
\text { value }\end{array}$ \\
\hline Age (years) & $50 \pm 9$ & $64 \pm 8$ & $41 \pm 8$ & $<0.0001$ \\
\hline \multicolumn{5}{|l|}{ Gender: } \\
\hline Male & $56 \%$ & $100 \%$ & $52 \%$ & 0.0333 \\
\hline Female & $44 \%$ & - & $48 \%$ & \\
\hline \multicolumn{5}{|l|}{ Hypertension state: } \\
\hline Hypertensive & $44 \%$ & $56 \%$ & - & 0.6098 \\
\hline Non-hypertensive & $56 \%$ & $67 \%$ & - & \\
\hline \multicolumn{5}{|l|}{ Diabetic state: } \\
\hline Diabetic & $33 \%$ & $81 \%$ & - & 0.0166 \\
\hline Non-diabetic & $67 \%$ & $19 \%$ & & \\
\hline Hemoglobin (g/dl) & $11.73 \pm 1.4$ & $11.8 \pm 1.66$ & $12.20 \pm 1.20$ & 0.6143 \\
\hline Creatinine (mg/dl) & $0.98 \pm 0.26$ & $1.08 \pm 0.27$ & $0.75 \pm 0.27$ & 0.0038 \\
\hline Cholesterol (mg/dl) & $175.1 \pm 25.2$ & $179.6 \pm 27.4$ & $147.2 \pm 21.3$ & 0.2755 \\
\hline Triglycerides (mg/dl) & $152.5 \pm 22.3$ & $177.2 \pm 25.4$ & $114.6 \pm 21.3$ & 0.0670 \\
\hline LDL (mg/dl) & $81.8 \pm 20.9$ & $82.5 \pm 24.6$ & $78.8 \pm 21.9$ & 0.8833 \\
\hline HDL (mg/dl) & $89 \pm 20.1$ & $90.3 \pm 30.1$ & $87.1 \pm 27.4$ & 0.9290 \\
\hline \multicolumn{5}{|l|}{ Troponin: } \\
\hline Positive & $93 \%$ & $100 \%$ & - & 0.4440 \\
\hline Negative & $7 \%$ & & - & \\
\hline CK (unit/liter) & $184.3 \pm 27.4$ & $189.5 \pm 35.3$ & - & 0.7146 \\
\hline CKMB (unit/liter) & $57.8 \pm 6.6$ & $45.3 \pm 7.2$ & - & 0.5383 \\
\hline
\end{tabular}

It shows no significant difference between the groups as regard to hypertension state, hemoglobin level, cholesterol level, triglyceride level, LDL level, HDL level, troponin, CK and CKMB ( $p$ value $>0.05$ ) but there was a significant difference between groups as regard age, gender and diabetic state $(p$-value $<0.05)$.

The age was significantly higher in both group II than in both group I and group ( $p$-value $<0.0001)$ as shown in Fig. (1). 


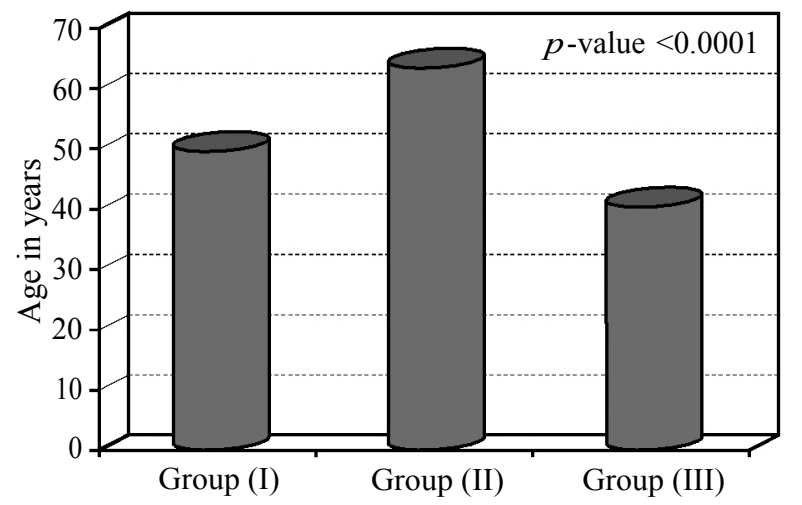

Fig. (1): Age distribution in groups studied.

The percentage of males was significantly higher in group II than in both group I and group III $(p$-value $=0.0333)$ as shown in Fig. (2).

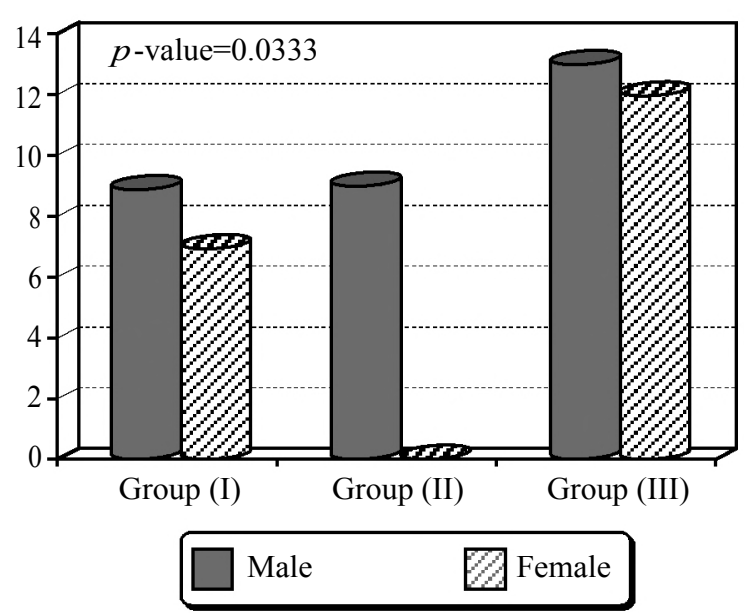

Fig. (2): Gender distribution in groups studied.

The percentage of diabetic patients was significantly higher in group II (than in group I ( $p$-value $=0.0166$ ) as shown in Fig. (3).

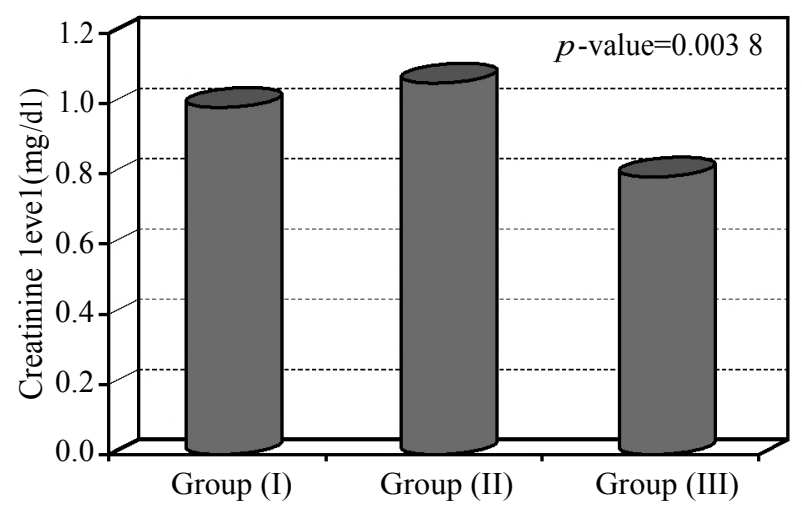

Fig. (3): Serum creatinine level in groups studied.

As regards serum ADAMTS 7 concentration in all groups studied, it ranged from 1.7 to $2.9 \mathrm{ng} / \mathrm{ml}$ with a mean of $2.34 \pm 0.45$ in group I. In group II, it ranged from 2.9 to $5.6 \mathrm{ng} / \mathrm{ml}$ with a mean value of $3.73 \pm 0.94 \mathrm{ng} / \mathrm{ml}$; while in group III, it ranged from 1.6 to $2.8 \mathrm{ng} / \mathrm{ml}$ with a mean value of $2.1 \pm 0.39$ $\mathrm{ng} / \mathrm{ml}$ (Table 2).

There was statistically significant increase in ADAMTS 7 concentration in group II (patients with ejection fraction $<40$ ) as compared with both group I (patients with ejection fraction 240 ) and group III (controls) ( $p$-value $<0.0001)$, while there was no statistically significant difference between group I and group III ( $p$-value $=0.2364)$ (Table 2$)$.

Table (2): Serum ADAMTS-7 level in groups studied.

\begin{tabular}{|c|c|c|c|}
\hline $\begin{array}{l}\text { ADAMTS } 7 \\
(\mathrm{ng} / \mathrm{ml})\end{array}$ & $\begin{array}{c}\text { Group I } \\
n=16\end{array}$ & $\begin{array}{c}\text { Group II } \\
n=9\end{array}$ & $\begin{array}{c}\text { Group III } \\
n=25\end{array}$ \\
\hline - Range & $1.7-2.9$ & $2.9-5.6$ & $1.6-2.8$ \\
\hline - Mean $\pm \mathrm{SD}$ & $2.34 \pm 0.45$ & $3.73 \pm 0.94$ & $2.1 \pm 0.39$ \\
\hline \multicolumn{4}{|c|}{ F-max test $32.38 p$-value $<0.0001^{*}$} \\
\hline $\begin{array}{l}\text { - Comparisons by } \\
\text { Fisher Exac }\end{array}$ & GI vs. GII & GI vs. GIII & GII vs. GIII \\
\hline - $p$-value & $<0.0001 *$ & 0.2364 & $<0.0001 *$ \\
\hline
\end{tabular}

We also found that there was a statistically significant negative correlation between ADAMTS 7 concentration and both ejection fraction and fractional shortening in acute myocardial infarction patients $(r=0.7110, p<0.0001) \&(r=0.6924, p$ value $=0.0001)$ respectively. While there was a statistically significant positive correlation between ADAMTS 7 concentration and both left ventricular end diastolic diameter and left ventricular end systolic diameter in acute myocardial infarction patients $(r=0.7310, p$-value $<0.0001)$ $\&(r=0.6914, p$-value $=0.0001)$, respectively. (Table $3)$, Figs. (4-6).

Our results showed that ADAMTS 7 cut-off was $2.9 \mathrm{mg} / \mathrm{ml}$ with a sensitivity of $93.33 \%$ and a specificity of $86.36 \%$ (Table 3 ).

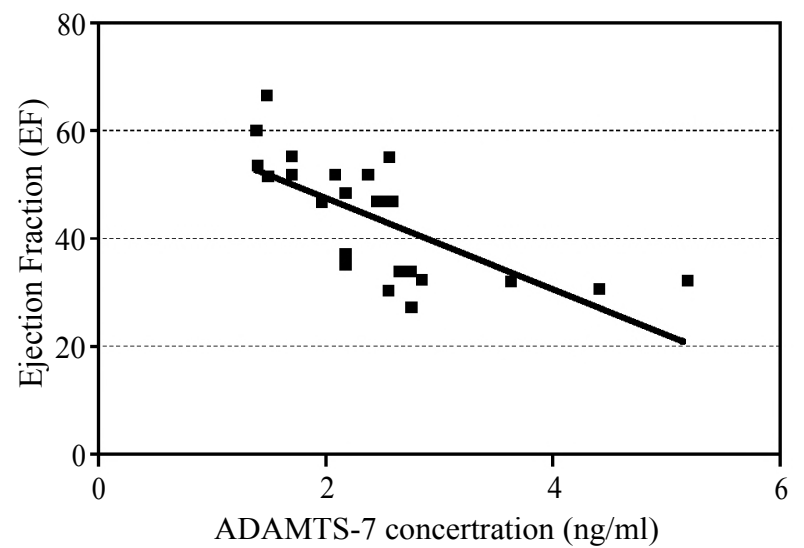

Fig. (4): Correlation between ADAMTS7 concentration and ejection fraction in acute myocardial infarction patients. 


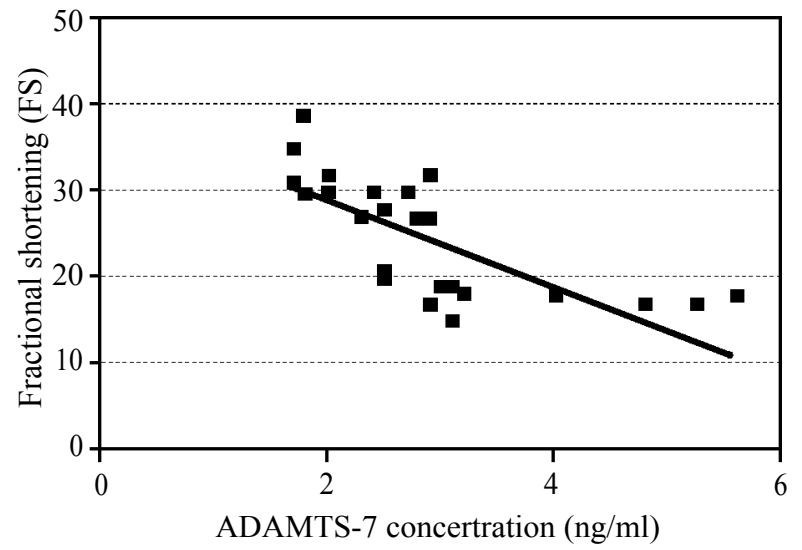

Fig. (5): Correlation between ADAMTS 7 concentration and Fractional Shortening (FS) in acute myocardial infarction patients.

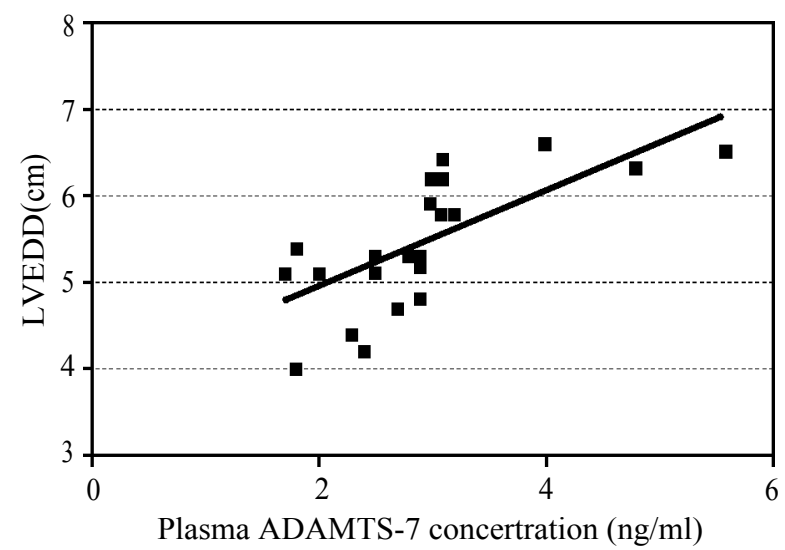

Fig. (6): Correlation between ADAMTS 7 concentration and Left Ventricular End Diastolic Dimensions (LVEDD) in acute myocardial infarction patients.

Table (3): Correlation between ADAMTS 7 and echocardiographic parameters.

\begin{tabular}{lcc}
\hline \multirow{2}{*}{$\begin{array}{l}\text { AMI patients } \\
\text { (GI \& GII) }\end{array}$} & \multicolumn{2}{c}{ ADAMTS 7 concertration } \\
\cline { 2 - 3 } & $r$ & $p$-value \\
\hline Ejection fraction & -0.7110 & $<0.0001^{*}$ \\
FS & -0.6924 & $0.0001^{*}$ \\
LVEDD & 0.7310 & $<0.0001^{*}$ \\
LVESD & 0.6914 & $0.0001^{*}$ \\
\hline
\end{tabular}

Table (4): Cut off, sensitivity and specificity of ADAMTS 7 as a prognostic marker for myocardial infarction.

\begin{tabular}{lccc}
\hline & Cutoff $\mathrm{ng} / \mathrm{ml}$ & Sensitivity & Specificity \\
\hline ADAMTS 7 & 2.9 & $93.33 \%$ & $86.36 \%$ \\
\hline
\end{tabular}

\section{Discussion}

Our study found that there was statistically significant increase in ADAMTS 7 concentration in patients with ejection fraction $<40$ as compared with both patients with ejection fraction > 40 and controls $(p$-value $=<0.0001)$.
The current study also found that there was a statistically significant negative correlation between ADAMTS 7 concentration and both ejection fraction and fractional shortening in acute myocardial infarction patients $(r=0.7110, p<0.0001) \&(r=$ $-0.6924, p$-value $=0.0001$ ) respectively. While there was a statistically significant positive correlation between ADAMTS 7 concentration with both left ventricular end diastolic diameter and left ventricular end systolic diameter in acute myocardial infarction patients $(r=0.7310, p$-value $<0.0001) \&$ $(r=0.6914, p$-value $=0.0001)$ respectively.

Our results are in accordance with Wu et al., 2015 who proved that there was a significant negative correlation between ADAMTS 7 concentration and both ejection fraction and fractional shortening in acute myocardial infarction patients and a significant positive correlation between ADAMTS 7 concentration and both left ventricular end diastolic diameter and left ventricular end systolic diameter in acute myocardial infarction patients [4]

Reilly et al., 2015 also reported that ADAMTS 7 is a novel locus in patients with angiographic coronary artery diseases who had myocardial infarction in comparison with patients with angiographic coronary artery disease without acute myocardial infarction [5].

Comparable results supporting our data have been reported by You et al., 2016 concerning the correlation between ADAMTS 7 and cardiovascular diseases in general. These authors found that ADAMTS7 locus confers high cross-race risk for development of coronary atheromatous plaque [6]

Patel et al., (2013) also found that ADAMTS 7 is a promising new therapeutic target in coronary heart disease as ADAMTS7 was found to play a role in neointima formation after arterial mechanical injury in animal model, by facilitating VSMC migration. Furthermore, a human genetic study had showed an association between DNA polymorphisms at the ADAMTS7 gene locus and risk of CAD. Functional studies had shown that a CADassociated polymorphism in the coding region of the ADAMTS 7 gene affects ADAMTS 7 maturation and VSMC migration. All this made ADAMTS 7 inhibition as a possible novel approach to treat CAD [7]

Wu et al., [4] explained the increased ADAMTS 7 concentration in patients with high degree of ventricular remodeling and low ejection fraction state $(<40)$ by degradation of Cartilage Oligomeric Matrix Proteins (COMP) that are present normally in extracellular matrix between cardiomyocytes 
and this is the responsible for ventricular remodeling process. Previous studies also demonstrated that ADAMTS 7 can participate in vascular smooth muscle migration and intimal thickening after vascular injury. So, it can lead to atherosclerosis and intimal thickening by degradation of COMP and this is a leading factor for myocardial infarction later on.

Some authors mentioned the benefit of ADAMTS 7 as a therapeutic target for decreasing ventricular remodeling and heart failure as the broad spectrum matrix metalloproteinases inhibitors of proteases may have severe disappointing side effects. However, Muller et al., 2016 reported that ADAMTS7 inhibitors may be safer as they have narrow substrate specificity due to various exosites located in the c-terminal region of the enzyme. So, more comprehensive studies should be made about proteases to limit their side effects and make these proteases as a safe therapeutic target [8].

\section{Conclusion:}

The results of this research showed that there was a significant increase in the mean value of ADAMTS 7 levels in patients with ejection fraction $<40 \%$ than in patients with ejection fraction $>40 \%$, so it may be used as a strong predictor for the development of left ventricular remodeling after acute myocardial infarction and this may be of a great value as a therapeutic target.

\section{Acknowledgments:}

This research was carried out without funding.

\section{Conflicts of interest:}

No conflicts of interest declared.

\section{Authors' contributions:}

All authors had equal role in design, work, statistical analysis and manuscript writing. All authors have approved the final article work.

\section{References}

1- THYGESEN K., ALPERT J.S., JAFFE A.S., et al.: Third universal definition of myocardial infarction. Circulation, Oct. 16; 126 (16): 2020-35, 2012.

2- SALTER R.C., ASHLIN T.G., KWAN A.P., et al.: ADAMTS proteases: Key roles in atherosclerosis? J. Mol. Med. (Berl.) Dec., 88 (12): 1203-11, 2010.

3- HANBY H.A. and ZHENG X.L.: Biochemistry and physiological functions of ADAMTS7 metalloprotease. Adv. Biochem., 1 (3), 2013.

4- WU W., ZHOU Y., LI Y., et al.: Association between plasma ADAMTS-7 levels and ventricular remodeling in patients with acute myocardial infarction. Eur. J. Med. Res., Mar. 21; 20: 27, 2015.

5- REILLY M.P., LI M., HE J., et al.: Identification of ADAMTS7 as a novel locus for coronary atherosclerosis and association of $\mathrm{ABO}$ with myocardial infarction in the presence of coronary atherosclerosis: Two genome-wide association studies. Lancet, Jan. 29; 377 (9763): 383-92, 2011.

6- YOU L., TAN L., LIU L., et al.: ADAMTS7 locus confers high cross-race risk for development of coronary atheromatous plaque. Mol. Genet. Genomics., Feb., 291 (1): 121-8, 2016.

7- PATEL R.S. and YE S.: ADAMTS7: A promising new therapeutic target in coronary heart disease. Expert. Opin. Ther. Targets., Aug., 17 (8): 863-7, 2013.

8- MULLER M., KESSLER T., SCHUNKERT H., et al.: Classification of ADAMTS binding sites: The first step toward selective ADAMTS7 inhibitors. Biochem. Biophys. Res. Commun., Mar. 11, 471 (3): 380-5, 2016. 


\section{العلاقة بين الآدامتز سبعة فى الدم وإعادة هيكلة البطين الآيسر بعد الإحتشاء الحماد في في عضلة العادة القلب}

يعتبر إعادة هيكة البطين الآيسر من آقوى عوامل الوفاة بعد الإحتشاء فى عضلة القلب. ولقد ظهر مؤخرا آن الآدامتز سبعة مرتبط إرتباطا وثيقا بتصلب الشرايين التاجية وإعادة هيكة البطين الإين هنين الآيسر.

الهدف من الدراسةة: هو تقييم العلاقة بين مستوى الآدامتز سبعة فى الدم وإعادة هيكلة البطين الآيسر بعد الإحتشاء الحاد فى عضلة

طرق البحث: تم إجراء هذه الدراسة على خمسين شخصا تم تقسيمه إلى مجموعتين بموجب حالتهم الصحية: مجموعة المرضى والتى

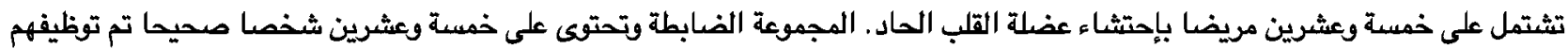

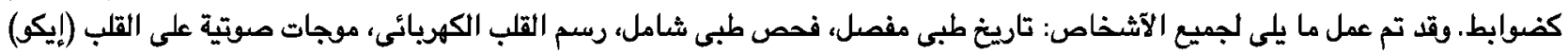

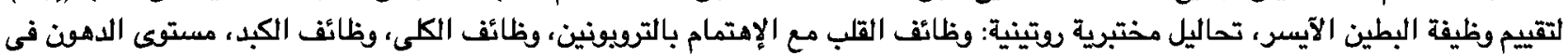
الدم، نسبة الآملاح فى الدم، صودة دم كاملة، تحليل مختبرى خاص وهو قياس مستوى الآدامتز سبعة فى الدم بواسطة وفئ تقنية الآليزا.

النتائج: كانت هناك زيادة ذات دلالة إحصائية في تركيز الآدامتز سبعة في المجموعة الثانية (المرضي ذوى قوة بطين إنقباضية آقل من

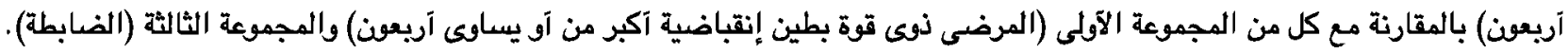

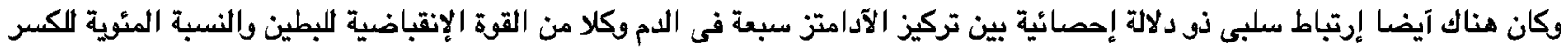

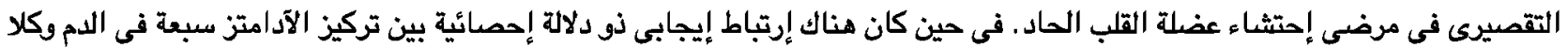

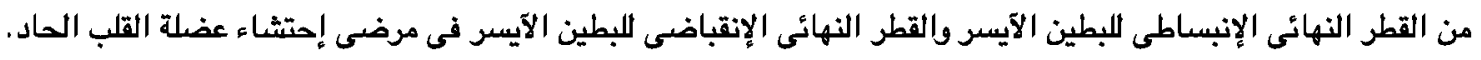

